\title{
SEMANTIC VARIATION AND THE GRAMMAR OF PROPERTY CONCEPTS
}

\author{
ITAMAR FRANCEZ \\ University of Chicago
}

ANDREW KoOntz-GARBoden

The University of Manchester

This article discusses the effects of variation in the meaning of property concept (PC) lexemes (Dixon 1982) on the form of predicative and comparative constructions. We demonstrate the existence of two kinds of PC lexeme, which differ systematically in how they participate in constructions expressing the truth conditions of PC predication. The first kind of lexeme is used in canonical predicative constructions, the other in predicative constructions that invoke possessive morphology or syntax. The differences between the two classes are observable both within a single language and crosslinguistically. The article argues that the morphosyntactic differences in the behavior of the two lexeme types are predictable from their lexical semantics. Specifically, we argue that some PC lexemes denote mass substances (in a technical sense) and therefore require possessive semantics to achieve the relevant truth conditions. A semantic theory for substancedenoting lexemes is developed, and a compositional analysis of the relevant constructions is presented for Ulwa, an endangered Misumalpan language of Nicaragua. We argue that assuming semantic variation is necessary, since the observed generalizations cannot be captured by extending existing semantic analyses of gradable adjectives to all PC lexemes.*

Keywords: property concepts, predication, possession, gradability and comparison, semantic variation, abstract mass nouns

1. InTRODUCTION. Dixon (1982) famously identified seven classes of PROPERTY CONCEPTS (PCs), notions that are consistently lexicalized as adjectives in languages with this lexical category. English examples from each of Dixon's classes are given in 1.

(1) Dixon's seven classes of PCs

$\begin{array}{ll}\text { DIMENSION } & \text { big, small, long, tall, short, wide, deep, etc. } \\ \text { AGE } & \text { new, young, old, etc. } \\ \text { VALUE } & \text { good, bad, lovely, atrocious, perfect, proper, etc. } \\ \text { COLOR } & \text { black, white, red, etc. } \\ \text { PHYSICAL } & \text { hard, soft, heavy, wet, rough, strong, hot, sour, etc. } \\ \text { SPEED } & \text { fast, quick, slow, etc. } \\ \text { HUMAN PROPENSITY } & \text { jealous, happy, kind, clever, generous, cruel, proud, } \\ & \text { etc. }\end{array}$

Throughout the article we use the term PC LEXEME for a morphologically simple lexical item encoding a PC. Such lexemes - for example, adjectives in English — are the basis for constructions such as $2 \mathrm{a}$ and $2 \mathrm{~b}$ (henceforth PC CONSTRUCTIONS), which can be said informally to express PREDICATION and COMPARISON, respectively.

\footnotetext{
* Our work on Ulwa would not be possible without the collaboration we enjoy with members of the community of Karawala and the Ulwa Language Project, particularly Alberto Santiago, Lorinda Martínez Lacayo, Clementina Simon, Abanel Lacayo, Francisco Santiago, and Kandler Santiago. We thank Mahamane Laoualy Abdoulaye for answering questions about Hausa. We have benefited from comments at presentations of this work at the annual meeting of the Linguistic Society of America (2011), The Philological Society, Salford University, Semfest, Spinfest, Stanford University, SULA 5 (MIT/Harvard), UC Berkeley, University of Chicago, University College London, University of Essex, University of Oxford, University of Paris 8, University of York, and the Workshop on Adjectives and Relative Clauses; from discussion with Mark Baker, Chris Kennedy, Louise McNally, Marcin Morzycki, Russell Schuh, and Eytan Zweig; and from the Language referees and editors, especially Heidi Harley. Data on Ulwa come from Koontz-Garboden's fieldnotes and Green 2004, where noted. This work was supported by the Arts and Humanities Research Council through Research Grant AH/H033645/1.
}

Printed with the permission of Itamar Francez \& Andrew Koontz-Garboden. (C) 2015. The authors permit unlimited use, distribution, and reproduction in any medium, provided the original work is properly cited. 
(2) PC constructions
a. Predication:
Hilary is tall.
b. Comparison:
Hilary is taller than you.

This article presents and analyzes a pattern of variation in the form of PC constructions, both within and across languages, having to do with the harnessing of possessive morphology/syntax in the expression of PC constructions. Specifically, we observe and demonstrate the existence of two kinds of predicative PC constructions, which we call CANONICAL and POSSESSIVE, and which differ in whether they employ a canonical strategy of predication employed also with predicate nominals (such as a copular construction), or whether they instead employ a strategy of predication based on possessive morphosyntax. The existence of a systematic possessive strategy of $\mathrm{PC}$ predication has not, as far as we know, been recognized, let alone analyzed, in the semantic literature on PC constructions. ${ }^{1}$

The contrast between canonical and possessive PC predication is demonstrated using data from Hausa (Chadic). Hausa has a small class of adjectival PC lexemes, which predicate using the canonical copular construction used with predicate nominals, as shown by comparison of the adjectival $3 \mathrm{a}$ with the predicate nominal in $3 \mathrm{~b}$. In what follows we call such PC lexemes NONPOSSESSIVE PREDICATING. ${ }^{2}$

(3) a. Audù dōgō nē.

Audu tall COP

'Audu is tall.'

(Jaggar 2001:457)

b. Audù dāraktă nē.

Audu director COP

'Audu is/was the director.'

(Jaggar 2001:457)

Hausa also has a large set of nouns, referred to in the descriptive literature as 'abstract nouns of sensory quality' (Parsons 1955), that express PCs. Such nouns can be used in predicative constructions, and when they are, the resulting predicative PC construction is form-identical to a possessive sentence, as shown in 4. PC lexemes like these, which trigger possession in predication, are called POSSESSIVE PREDICATING.

(4) a. Mună dā karfĩ.

we.cONT with strength

'We are strong.'

b. Yārinyă tana dà zōbè.

girl she.CONT with ring

'The girl has a ring.'

(Newman 2000:224)

(Newman 2000:222)

Predication with PC adjectives and predication with PC nominals thus contrast with one another morphosyntactically; while the former entails use of a copular element, the latter does not, but instead makes use of morphosyntax otherwise implicated in the expression of possessive predication. We show further that the two classes of PC lexemes contrast in the way they participate in comparative constructions. There are comparative constructions that are dedicated to - that is, can only be constructed with-those

\footnotetext{
${ }^{1}$ Isolated instances, however, have been documented in the functional-typological literature on lexical categories and predication, for example, Wetzer 1996:178. Very little attention is devoted to them even there, though.

${ }^{2}$ Abbreviations used in glosses are as follows: CONT: continuative, COP: copula, EXCL: exclusive, INCL: inclusive, M: masculine, NEG: negative, NONFUT: nonfuture, PL: plural, POSS: possessive, PRF: perfect, PRON: pronoun, PST: past, SENT.KA: 'sentential $k a$ ', SG: singular, TOP: topic.
} 
lexemes that participate in possessive predication. In Hausa, for example, the canonical comparative construction is one that makes use of an 'exceed' verb, as illustrated in 5.

(5) Jirgī yā fì mōtă girmā.

plane it exceed car largeness

'A plane is bigger than a car.'

(Newman 2000:93)

Adjectival PC lexemes, by contrast, cannot serve as the PC argument of the 'exceed' verb (Newman 2000:93, Russell Schuh, p.c.), as illustrated by the ungrammaticality of 6, which replaces the nominal PC lexeme girm $\bar{a}$ 'largeness' in 5 with its adjectival minimal-pair counterpart bàbba 'big'.

(6) *Jirgī yā fi mōtă bàbba.

plane it exceed car big

intended: 'A plane is bigger than a car.'

(Newman 2000:93)

The article has two main objectives. The first is to establish the crosslinguistic robustness of the distinction between canonical and possessive PC predication. The second is to propose and develop a simple hypothesis about what underlies this distinction. The hypothesis is that the distinction is rooted in the lexical semantics of PC lexemes. Specifically, we hypothesize that there are (at least) two types of PC lexemes, differing in denotational semantics. We refer to the first class as ADJECTIVALLY DENOTING, and to the other as SUBSTANCE DENOTING. We propose a denotation for substance-denoting lexemes that affords a simple motivation for the occurrence of possessive morphosyntax in PC predication and that also makes sense of the contrasting behavior between adjectivally denoting and substance-denoting PC lexemes in comparative constructions. Substance-denoting PC lexemes, on our analysis, have mass denotations, which we model using the algebraic approach standard since Link 2002 [1983]. We call these lexemes substance denoting because, intuitively, their denotations can be thought of as the (abstract) substances one might informally associate with English abstract mass nouns such as strength and beauty. Following the same intuition, possessive PC predication involves relating individuals to 'portions' of such substances that they have. We develop a compositional model-theoretic semantics that models this intuition while capturing the main general semantic characteristics of PC constructions familiar from the literature on gradability and comparison. As we show, different languages make use of different possessive strategies in expressing possessive PC predication. Our analysis is constructed around the particularly interesting (and apparently rare) strategy found in Ulwa, a Misumalpan language of Nicaragua.

Adjectivally denoting PC lexemes, by contrast, denote whatever it is that adjectives denote. As discussed in $\S 5$, what this denotation is is a matter of significant theoretical debate in the literature on gradability and comparison (Kamp 1975, Cresswell 1977, Klein 1980, von Stechow 1984, Heim 1985, Bierwisch 1989, Kennedy 1999, Moltmann 2009, Husband 2010, among many others). We take no position on the correct analysis of adjectives in this article, except to assume that they do not denote substances. This view, we show, is motivated by both their semantic and morphosyntactic behavior.

Our main theoretical claim is that the fact that possessive PC constructions are possessive receives a natural explanation on the assumption that such constructions are built on substance-denoting lexemes. Specifically, since such lexemes denote substances, using them in a canonical predicative construction does not yield the truth conditions of a predicative PC construction. The role of possessive morphosyntax is to produce the correct truth conditions by contributing a semantic relation between indi- 
viduals and substances. Adjectivally denoting PC lexemes, in contrast, already have denotations that allow them to be used in a canonical predicative construction with the right truth conditions. We thus arrive at an explanation of the morphosyntactic variation in PC constructions between possessive and canonical realization that derives it from semantic variation in the lexicon. We state this claim as the LEXICAL SEMANTIC VARIATION HYPOTHESIS, as in 7.

(7) The lexical semantic variation hypothesis: Substance-denoting PC lexemes require possessive semantics to achieve the truth conditions of PC constructions. Adjectivally denoting PC lexemes do not. Possessive morphosyntax contributes possessive semantics, and hence surfaces only with PC constructions built on substance-denoting PC lexemes.

In arguing for 7 , we consider in $\S 5$ the possibility that theories of the semantics of adjectives might be extended to possessive predicating PC lexemes to capture the morphosyntactic contrast between the two classes of PC lexemes we observe without positing semantic variation. We show that such an extension fails to capture a number of important contrasts, both semantic and morphosyntactic, and conclude that variation in the denotation of PC lexemes of the kind we argue for is warranted. The overall conclusion is that variation in the meanings of PC lexemes is responsible for variation in the morphosyntactic form of PC constructions. Both the semantic variation and its morphosyntactic consequences have previously gone unappreciated in the theoretical literature on the topic.

The structure of the article is as follows. We begin in the next section by laying out the empirical landscape, exemplifying both the generality of possessive strategies of predication crosslinguistically and some of the morphosyntactic diversity with which they can be implemented. We then show that the same classes of PC lexemes that give rise to possession in predication also give rise to special behavior in comparative constructions (§3). In $\S 4$ we discuss the hypothesis that possessive strategies encode substance possession, presenting a semantic theory of substances and substance possession and then exemplifying this proposed semantics in a compositional analysis of the Ulwa PC constructions described above. Section 5 considers in broader perspective our theory of the variation we observe in the morphosyntactic shape of PC constructions and considers (and rejects) potential alternatives. Finally, we offer some concluding remarks (§6).

2. Possessive STRATEgIES OF PREDICATION. The first morphosyntactic property characterizing possessive predicating PC lexemes, from which their label is derived, is the use of possessive morphology or syntax in predicative PC constructions. This section demonstrates this empirical observation in a variety of languages. It shows that possessive strategies can take a range of morphosyntactic forms, depending on what morphosyntactic strategies for the expression of possession are available in specific languages. The examples given here are not intended as an exhaustive list, but suffice for illustration of the generality of the phenomenon.

Possessive strategies of predication are, in fact, far from exotic, and distinguish nominally encoded PCs from adjectival ones in very familiar Germanic and Romance languages such as German and Spanish. The data in 8 demonstrate the contrast for Spanish. Adjectives in Spanish exhibit a canonical pattern of predication in taking a copula, like predicate nominals $(8 \mathrm{a}, \mathrm{b})$. Nominally encoded PCs, by contrast, predicate with a possessive construction $(8 \mathrm{c}, \mathrm{d})$.

(8) a. Kim es alto.

Kim is tall

'Kim is tall.' 
b. Kim es un professor.

Kim is a professor

'Kim is a professor.'

c. Kim tiene sueño.

Kim has tiredness

'Kim is tired.'

d. Kim tiene un carro.

Kim has a car

'Kim has a car.'

The data in 9 demonstrate the same for German.

(9) a. Ich bin hungrig.

I am hungry

'I am hungry.'

b. Ich bin Arzt.

I am a.doctor

'I am a doctor.'

c. Ich habe Hunger.

I have hunger

'I am hungry.'

d. Ich habe ein Auto.

I have a car

'I have a car.'

In Germanic and Romance, only a few PC lexemes behave in this way, and these seem to be restricted to PCs describing temporary experiences, that is, concepts belonging to what Dixon (1982) called the HUMAN PROPENSITY CLASS. In the languages described below, the use of possessive strategies is more extensive, covering practically all PC lexemes in languages like Ulwa, ${ }^{3}$ and spanning several possessive constructions in languages like Hausa.

2.1. Hausa. As mentioned in the introduction, the descriptive literature on Hausa (Newman 2000, Jaggar 2001) recognizes a large class of PC words lexicalized as nouns. These are traditionally called in the literature, following Parsons (1955), 'abstract nouns of sensory quality’, or ANSQs (Newman 2000:Ch. 2, Jaggar 2001:103), and number about sixty PC words, some of which are listed in 10.

(10) Some ANSQs in Hausa (Newman 2000:13, Jaggar 2001:103ff.): dād ‘̀ 'pleasantness, niceness'; nauȳ 'heaviness'; tsāmī 'sourness, acidity'; wār $\bar{\imath}$

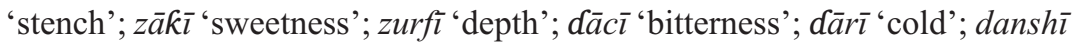
'dampness, moistness'; fād $\bar{\imath}$ 'breadth, width'; gautsī 'brittleness'; kaifì 'sharpness'; Karfì 'strength'; lāmī 'tastelessness'; laushī 'softness'; nauȳ̄ 'heaviness' ...

As shown in 3 and 4 above, regular nominal predication and PC predication with ANSQs do not pattern together. The former is expressed as a copular construction, whereas the latter is expressed as a possessive construction. In Newman's words: 'HAVE sentences with complements consisting of abstract nouns indicate predicative qualities' (2000:224).

Possessive strategies in Hausa are not restricted to the prepositional possessive construction illustrated in 4 . Hausa has a range of constructions that are used for expressing

${ }^{3}$ See Koontz-Garboden \& Francez 2010:213 for five possible exceptions. 
possession (Abdoulaye 2006), many of which can also be used for predication of ANSQs. For example, there are two existential constructions that serve this function. The first of these constructions is given an informal characterization by Newman that succinctly summarizes how it works: 'An existential structure made up of àkwai plus a pronoun extended by dà plus an NP indicates possession ... The thing possessed, indicated by the dà phrase, is usually a quality rather than a concrete object' (2000:179).

The data in 11 exemplify this construction.

(11) a. àkwai shì dà wăyō.

exists him with cleverness

'He is very clever.'

(Newman 2000:179)

b. àkwai sù dà kyâu!

exists 3PL with beauty

'They're really beautiful!'

(Jaggar 2001:465)

c. mutănen nàn, àkwai sù dà rōwă.

men these exists them with miserliness

'These men, they are misers.'

(Newman 2000:226)

That this construction is implicated in the grammar of possession more generally is illustrated by the data in $12 .{ }^{4}$

(12) Ràshiidaa mù tafì gidaa, àkwai mù dà tuwo-n-mù à gidaa!

Rashida 1PL go home exist 1PL with food-of-1PL at home

'Rashida, let us go home, we HAVE our food at home!' (Abdoulaye 2006:1139)

The data in 13 show that this construction is restricted in its use to the class of PC nominals. While the adjectival PC word is judged unacceptable in construction 13a, its PC nominal minimal pair is licit (13b), a fact that further illustrates the split between the two classes of PC lexeme in the language.

(13) a. *Bàlki àkwai tà dà doogoo.

Balki exists her with tall intended: 'Balki is really tall.'

(Mahamane Laoualy Abdoulaye, p.c.)

b. Balki àkwai tà dà tsawoo.

Balki exists her with tallness

'Balki is really tall.'

(Mahamane Laoualy Abdoulaye, p.c.)

According to both Wetzer (1996:178) (via personal communication with Russell Schuh) and Jaggar (2001:465), PC predication can also be expressed by an existential construction 'where the quality-denoting NP is the existential subject' (Jaggar 2001:465). In other words, in this construction the pivot is the property itself, with the bearer of the property the argument of a prepositional phrase, as exemplified in $14 .^{5}$

\footnotetext{
${ }^{4}$ There are a number of features that are not yet well understood in relation to the syntax and semantics of this construction. For example, according to Abdoulaye (2006), it can only host pronouns, not full NPs, a fact illustrated by (i).

(i) *àkwai Bàlki dà wāyō. exists Balki with cleverness 'Balki is really clever.'

(Abdoulaye 2006:1139)

NPs seem to be licit, however, in the presence of an anaphoric pronoun, as shown by $13 \mathrm{~b}$ below. For our purposes, all that matters is that a construction used for the expression of nominal possession is also used for the expression of PC predication, and that it distinguishes between two kinds of PC lexemes.

${ }^{5}$ Note that gàre and $g a$ in $14 \mathrm{a}$ and $14 \mathrm{~b}$ are allomorphs of the same morpheme, the latter used when followed by a personal pronoun, the former used everywhere else (Newman 2000:467).
} 
(14) a. (àkwai) hankàlī gàrē shì.

exists cleverness at 3sG.M

'This boy, he's clever alright!'

(Jaggar 2001:465)

b. akwai fad'i ga kogin nan.

exists width at river this

'This river is wide.'

(Wetzer 1996:178, via p.c. with Russell Schuh)

c. àkwai hāzikancì gàrē shì.

exists cleverness at him

'There is cleverness with him.'

(Newman 2000:182)

Example 15 shows that this construction can be used to express possession as well.

(15) àkwai kudī gàrē kà?

exists money at you

'Do you have any money on you?'

(Jaggar 2001:466)

2.2. Нuiтото. A similar possessive strategy is found in Huitoto, a Huitotoan language of Colombia. According to Minor and colleagues (1982:42), Huitoto has a class of adjectival PC words, as well as a class of nominal ones. While the former predicate directly (16a), the latter require the suffix -re (16b), which is also the suffix that expresses possessive 'have' in the language, as shown in 16c.

(16) Huitoto (Huitotoan; Colombia)

a. jofo àillue.

house big

'The house is big.'

(Minor et al. 1982:42)

b. rozilli naimé-re-de.

pineapple sweet-HAVE-3sG

'The pineapple is sweet.'

c. jofó-re-di-cai.

house-HAVE-NONFUT-1PL

'We have a house.'

(Minor et al. 1982:101 in Stassen 2009:183)

As far as we have been able to tell, this possessive strategy is not used with predicate nominals and adjectives; 17 shows that predicate nominals that do not encode PCs are predicated by simple juxtaposition of subject and predicate, and 18 shows the same for adjectives.

(17) cue moo cai illaima.

1SG.PRON father 1PL.PRON captain

'My father is our captain.'

(Minor et al. 1982:62; glossed with aid of Minor \& Minor 1987)

(18) jofo àillue. house big

'The house is big.'

(Minor et al. 1982:42)

2.3. BisA. A somewhat more exotic pattern is found in Bisa, a Mande language spoken in northern Ghana and southern Burkhina Faso. In Bisa possession is expressed by existential constructions. The Bisa existential is exemplified in 19.

(19) Wusu ta-w.

God exist-in

'God exists.'

(Naden 1982:212)

A possessive sentence in Bisa is an existential in which the NP argument of the existential predicate is a possessive NP. Possessive NPs are formed by juxtaposition of possessor and possessed, as shown in 20. The possessive construction is exemplified in 21 . 
(20) Moว lu bor naa-w.

I wife came this-at

'My wife came here.'

(21) Mos lu ta-w.

I wife exist-in

'I have a wife.'

(Naden 1982:212)

(Naden 1982:212)

As shown in 22, PC predication, at least with some PC lexemes, is expressed as a possessive construction in which the possessed noun expresses the PC.

(22) a. A gwili ta-w.

3sG weight exists-in.

'It is heavy.'

(Naden 1982:212)

b. A gweli ta-w.

3sG beauty exists-in

'She is pretty.

(Naden 1982:213)

As 23 shows, predicate nominals in Bisa predicate with a copula, not with a possessive strategy.

\section{(23) Tiikya awo n. \\ teacher he $\mathrm{COP}$ \\ 'He is a teacher.'}

(Naden 1982:213)

Naden's discussion clearly indicates that not all PC lexemes in Bisa participate in this strategy, but he does not provide elaboration beyond this; the key point is simply that at least some PC lexemes in Bisa invoke a possessive strategy.

The data considered so far establish quite clearly that some PC lexemes trigger possessive strategies of predication, and that in several unrelated languages, such strategies distinguish two kinds of PC lexemes. Recall that the main theoretical claim of this article is that these two classes are characterized by different lexical denotations, as discussed in $\S 4$. If this claim is correct, it is entirely possible that there are languages in which all PC lexemes have one or the other denotation, and hence belong to one or the other class. The language discussed next, Ulwa (Misumalpan; Nicaragua), seems to be one in which nearly all, if not all, PC lexemes are possessive predicating.

2.4. Ulwa. The possessive strategies shown so far are all instances of what Stassen (2009) calls 'predicative possession', that is, the structure used to express 'have' sentences. Ulwa shows an interestingly different possessive strategy of predication, built not on predicative possession but instead on nominal possession. ${ }^{6}$ The crucial properties of Ulwa are the following:

(i) PCs are encoded by morphologically bound precategorial roots.

(ii) The words that translate English adjectives are nouns, derived from such roots by affixing the morpheme $-k a$.

(iii) The same morpheme marks the possessed noun in a possessive noun phrase. The feature in (i) is a robust fact of Ulwa grammar, made clear from the discussions and data in Green 1999, Hale \& Salamanca 2002, Koontz-Garboden 2007:Ch. 6, 2009c, and

\footnotetext{
${ }^{6}$ See Kim \& Koontz-Garboden 2013 for data showing that a similar kind of possessive strategy is found, albeit with fewer PC lexemes, in the Mexican isolate Huave.
} 
Koontz-Garboden \& Francez $2010 .^{7}$ The features in (ii) and (iii) are discussed in Koontz-Garboden \& Francez 2010 and illustrated here in turn. ${ }^{8}$

In Ulwa possessive NPs, possession is marked on the possessed noun. The possessive marker agrees with the possessor, according to the paradigm in 24, illustrated in 25 .

(24) Nominal possessive paradigm (Green 1999:78)

$\begin{array}{llll}1 \mathrm{SG} & -\mathrm{ki} & \text { 1PL.EXCL } & -k i-n a \\ 2 \mathrm{SG} & -\mathrm{ma} & 2 \mathrm{PL} & -\mathrm{ma}-n a \\ 3 \mathrm{SG} & -\mathrm{ka} & \text { 3PL } & -k a-n a \\ & & \text { 1PL.INCL } & \text {-ni }\end{array}$

(25) a. yang pan-ki

$1 \mathrm{sG}$ stick-1sG

'my stick'

b. man pan-ma

2SG stick-2sG

'your stick'

c. alas pan-ka

3sG stick-3sG

'his/her stick'

etc.

The third-person possessive suffix, $-k a$, illustrated in $25 \mathrm{c}$, appears on PC roots in predicative (and adnominal) position, as illustrated in 26.

(26) Yang as-ki-na minisih-ka.

1sG shirt-1sG dirty-KA

'My shirt is dirty.'

(Green 2004:asna)

Koontz-Garboden \& Francez 2010 and Koontz-Garboden 2016 show, based on Misumalpan diachrony, that the morpheme - $k a$ that appears in PC constructions and the one that marks possessed nouns are one and the same, rather than accidental homophones. ${ }^{9}$ In brief, the observation is that in the history of Misumalpan, when the third singular possessive suffix underwent a shift in its phonological shape, the PC suffix also underwent precisely the same shift, showing that, at least at the time of the shift, the two suffixes were actually one and the same.

Ulwa also has a possessive strategy based on predicative possession, using the nonverbal predicate watah 'have', illustrated in $27 .{ }^{10}$

\footnotetext{
${ }^{7}$ As discussed in detail in Koontz-Garboden \& Francez 2010:210-14, the use of PC roots in their bare form is marginal, though attested (to varying degrees and with unstable judgments) in contexts in which the root appears to cliticize to some surrounding element that is at least bimoraic in phonological weight. The question is why the morpheme that is used to turn the bound roots into morphologically free words is specifically possessive.

${ }^{8}$ Also discussed in Koontz-Garboden \& Francez 2010:213-14 is the fact that while nominal possessive affixation agrees in person and number with the possessor, the possessive morphology on PC roots never agrees with its subject in person and number. As noted there, 'given that PC words in - $k a$ are nouns, and that nouns in predicative position do not show agreement with their argument, it is unsurprising that there is no agreement for person/number on the predicative PC $-k a$ word. Furthermore, that it is the third person form of $-k a$, rather than some other form, which is used with PC roots is unsurprising, as third person commonly surfaces as the default form in non-agreeing contexts' (2010:214).

${ }^{9}$ Koontz-Garboden 2016 additionally shows, based on a combination of the same diachronic argument and typological observations, that $-k a$ does not realize a morphome (in the sense of Aronoff 1994 and Maiden 2005).

${ }^{10}$ The 'sentential $k a$ ' illustrated in 27 is, as best we can tell, unrelated to the nominal possessive $-k a$ under discussion here. See Koontz-Garboden 2009 b for details.
} 
(27) Muih luih ya pâpangh watah ka. person all the father have SENT.KA 'Everyone has a father.'

(Green 2004:pâpangh)

This is occasionally also used for PC predication, as in 28.

(28) Yâka û-ka yâka yûh-ka.

An tarat watah ka.

that house-3sG.POss that long-3sG.POSS and tall have SENT.KA

'That house is long. And it's tall.'

(Oct09-109)

This strategy is less common than the nominal possessive strategy laid out above, though is still well attested in naturally occurring speech.

Thus, Ulwa PC predication involves a possessive strategy of predication, including a strategy built on nominal possession. In $\S 4$, we use Ulwa to exemplify the semantics we propose for possessive predicating PC lexemes. ${ }^{11}$

2.5. Summary. To summarize, this section has shown that possessive strategies of predication are quite common crosslinguistically. In the languages looked at, possessive strategies are never used with predicate nominals; they are only used with precategorial or nominally encoded PC lexemes, and never with adjectival ones. Possessive strategies seem to come in as many forms as there are possessive constructions; the patterns observed in this section are schematized in Table 1.

$\begin{array}{lll}\begin{array}{l}\text { TYPE } \\ \text { Nominal possessive marking } \\ \text { 'have' }\end{array} & \begin{array}{l}\text { LANGUAGE } \\ \text { Ulwa, Huitoto, Hausa }\end{array} & \begin{array}{l}\text { PARAPHRASE } \\ \text { She has strength. } \\ \text { She is with strength. }\end{array} \\ \begin{array}{ll}\text { Existential: BEARER pivot } \\ \text { Existential: PROPERTY pivot }\end{array} & \text { Hausa } & \text { There is her with strength. } \\ \text { Existential: possessive NP pivot } & \text { Bisa } & \text { There is strength at her. }\end{array}$

TABLE 1. Possessive strategies of predication.

To end this section, we point out a potential empirical generalization. It seems to be the case that possessive PC constructions only and always involve nominal or root PC lexemes, and never adjectives. It is not clear to us at this point whether the stronger claim that nominal encoding of PCs always triggers possession-based predication is also true, though see Jenks et al. 2013 for relevant discussion based on facts in Basaá (Bantu; Cameroon). This opens up an interesting set of questions about whether there are generalizations to be made about the correlation between lexical categories and predication strategies, and, if so, what explains them. We leave these questions for future research.

3. Comparatives Dedicated to Possessive PRedicating PC lexemes. The class of possessive predicating PC lexemes identified in the previous section on the basis of behavior in predicative constructions can also be identified, in at least two ways, on the basis of the morphosyntax of comparative constructions in some languages.

First, in Ulwa, comparatives are built on top of the possessive strategy, as illustrated in 29, where the comparative is formed with the degree modifier kanas 'more' in combination with the PC word $y \hat{u} h-k a$ 'tall', marked with the possessive $-k a$.

(29) Abanel ya kanas yûh-ka Clementina karak.

Abanel the more tall-3sg.Poss Clementina with

'Abanel is taller than Clementina.'

(Jan11-14)

${ }^{11}$ We do this on the basis of the nominal possessive construction, the most productive in the language. See Francez \& Koontz-Garboden 2015 for additional details and analysis of the watah 'have' construction in Ulwa. 
In Ulwa, all PC lexemes are possessive predicating (modulo n. 3, 7), and as such, we see no contrast between classes of PC word in the comparative. In Spanish and German, however, the comparative construction that builds on a possessive strategy distinguishes nominal from adjectival PC lexemes. As illustrated in 30, the comparative with nominal PCs is formed using possessive 'have' with the degree modifiers translating as 'more' (más in Spanish, mehr in German).

(30) a. Papi tiene más sueño que yo.

Dad has more tiredness than me

'Dad is more tired than me.' 12

b. Er hatte mehr Hunger als ich.

he had more hunger than I

'He was hungrier than me.'

This contrasts with the comparative construction these languages employ with adjectives, which, unsurprisingly, has no overt exponent of possession, makes use of a copula, and, in the case of German, features comparative morphology (31).

(31) a. Juan es más alto que Pedro.

Juan is more tall than Pedro

'Juan is taller than Pedro.' 13

b. Ich bin älter als du.

I am older than you

'I am older than you.'

Adjectives cannot be used with the possessive strategy comparative, as shown by 32 a and 33a, and likewise the possessive predicating lexemes cannot be used with the comparative used with nonpossessive predicating lexemes with the intended meaning, a fact shown by $32 \mathrm{~b}$ and $33 \mathrm{~b}$.

(32) a. *Papi tiene más alto que yo.

Dad has more tall than me intended: 'Dad is taller than me.'

b. *Papi es más sueño que yo.

Dad is more tiredness than me intended: 'Dad is more tired than me.'

(33) a. *Ich habe mehr alt als du.

I have more old than you intended: 'I am older than you.'

b. *Ich bin mehr Hunger als du.

I am more hunger than you

intended: 'I am hungrier than you.'

In some languages that have lexemes of both classes, possessive predicating and nonpossessive predicating, there is a comparative construction that targets possessive predicating lexemes but does not build on the possessive strategy. This was already illustrated for Hausa by the data in 5 and 6, repeated in 34a,b, respectively, which show that the comparative with $f i$ 'exceed' can be used with possessive predicating PC lexemes (i.e. the class of ANSQs) (34a), but not with the smaller class of nonpossessive predicating adjectives (34b).

\footnotetext{
$12 \mathrm{http}: / /$ album.enfemenino.com/album/see_539867_12/Hector.html

${ }^{13} \mathrm{http} / / /$ perso.wanadoo.es/usoderazonweb/html/conten/argum/arganalo/analo2.pdf
} 
(34) a. Jirḡi yā fi mōtă girmā.

plane it exceed car largeness

'A plane is bigger than a car.'

(Newman 2000:93)

b. *Jirgī yā fi mōtà bàbba.

plane it exceed car big

intended: 'A plane is bigger than a car.'

(Newman 2000:93)

In sum, in languages for which we have data, the same lexemes that give rise to possessive strategies of predication also give rise to special behavior in comparative constructions. In Ulwa, Spanish, and German, a possessive strategy is found not only in the predicative construction, but in the comparative as well. In the latter two languages, the possessive comparative construction targets nominal PC lexemes to the exclusion of adjectival PC lexemes. In Hausa, there is a special comparative construction in which only lexemes of the possessive predicating class can be used, a fact that further shows that lexemes in this class are different from lexemes in the nonpossessive predicating class.

4. Possessive strategies and substance POSSESSiOn. The hypothesis explored here (building on Koontz-Garboden \& Francez 2010 and Francez \& Koontz-Garboden 2010) is that possessive strategies are semantically motivated. In particular, they are motivated by the denotation of the PC lexemes that are found in them. We suggest that possessive strategies encode possessive semantics, and specifically a semantics of SUBSTANCE POSSESSION, where what is meant by 'substances' is made precise below. Intuitively, substances are abstract mass entities, and substance-denoting expressions denote the set of all 'portions' of the relevant substance. Therefore, the content of PC predication cannot be expressed by directly predicating a substance-denoting term of an individual. For example, suppose for the sake of illustration that the PC encoded by the English adjective strong were instead encoded only by the noun strength, and suppose that this noun denotes a substance in our sense, that is, a mass entity called 'strength'. Just like the mass noun water denotes the set of all portions of water, so strength denotes the set of all portions of strength. Consequently, directly predicating strength of an individual $a$ would yield the content that $a$ is a portion of strength, which is not the intended content of a predicative PC construction with this PC (cf. Felicia is strong). Thus, in order to express this content with a substance-denoting lexeme, some other means must be found. Our suggestion is that a semantics of substance possession, and consequently possessive morphosyntax, is that means.

In philosophical jargon, predication is standardly talked about in terms of substance possession. Thus, we talk of things HAVING substances, and take sentences such as those in 36 to be roughly truth-conditionally equivalent.

(35) a. Krishna is wise. $\approx$

b. Krishna has wisdom.

The job of a theory of possessive strategies is to provide a model-theoretic account of substances and substance possession that can be used in assigning a compositional semantics to predicative and comparative PC constructions. Such a semantics must capture the crosslinguistically invariable aspects of the semantics of $\mathrm{PC}$ constructions, in particular the well-known context dependence of predicative PC sentences (see Kennedy 2007 for an overview). In this section we develop such a theory, starting with an elaboration of our theory of substances and substance possession. We then illustrate how the possessive strategy is implemented compositionally in one language by developing compositional analyses of the Ulwa predicative and comparative constructions.

4.1. Substances. Our proposal is to model substances analogously to the denotations of mass nouns in Link 2002. This is motivated by the fact that when PC notions 
are encoded by nouns, these are generally mass nouns. This is the case, for example, for English nominal PC terms such as strength, hunger, and so forth, for the nominal PC terms in Romance and Germanic, and for Hausa as discussed above. The semantics of abstract mass nouns has remained largely unexplored in the linguistic literature until recently (see Moltmann 2009, Nicolas 2010). ${ }^{14}$ As a consequence, there is no standard model-theoretic treatment of them. For current purposes, we simply adopt, with very little modification, Link's (2002) mereological approach to mass nouns. ${ }^{15}$

Mass nouns like water are predicates over a domain that is mereologically ordered. If something is water, then any part of it is also water, and any two portions of water can be 'fused' into a single portion of which they are both parts. Similarly, a substance is a predicate over a domain that is mereologically ordered. If something is a portion of strength, then any part of it is also a portion of strength, and any two portions of strength can be 'fused' into a portion of which they are both parts. The crucial assumptions required to flesh out this intuition are as follows. Let $\mathcal{A}$ be a nonempty set of portions. Substances are subsets of $\mathcal{A}$ that have the structure of a join semilattice (with no bottom element) with the join operation $\sqcup$ (i.e. $\sqcup$ is commutative, indempotent, and associative). $\sqcup$ induces an ordering relation $\preceq$ on $\mathcal{A}$, which can be thought of as a 'partof' relation.

(36) For any $p, q \in \mathcal{A}, p \preceq q \Leftrightarrow p \sqcup q=q$

Substances are closed under $\sqcup$. Thus, two portions of any substance have a 'fusion' that is also a portion of the substance. Gradability is modeled as an ordering on the portions of substances with the following two postulates.

- P1: Any substance $P \subset \mathcal{A}$ is ordered by a total preorder $\leq$, intuitively thought of as 'smaller or equal to'.

- P2: The preorder $\leq$ preserves the mereological part-of relation, so that given a substance $P$, and two portions $p, q \in P: p \preceq q \rightarrow p \leq q$

P1 states that any two portions of a substance are comparable in 'size'. Two distinct portions can be of the same size, or else one can be bigger than the other. P2 states that a portion that is a part of another portion is smaller than the portion it is part of. In the analysis of PC constructions, the mereological part-of relation plays no role, whereas the preorder $\leq$ plays a crucial one. However, this does not mean that the mereological structure plays no role in their semantics, as discussed further in $\S 4.5$.

4.2. Substance POSSESSION. A key element of our proposal is that PC predication with substances takes the form of substance possession, because substance-denoting expressions cannot be directly predicated of individuals with the intended meaning. To illustrate this, we need some notation. For convenience, we use boldfaced English nominalizations as constants over substances. For example, strength is the constant naming the substance of strength, that is, the set of all portions of strength. Let $P, Q$ be variables over substances, that is, subsets of $\mathcal{A}$ or the characteristic functions thereof, and let $p, q$ be variables over portions. If $\alpha$ is a substance-denoting expression denoting the substance strength, the denotation of $\alpha$ is written as the function characterizing all and only the portions of this substance, as in 37.

(37) $\llbracket \alpha \rrbracket=\lambda p$.strength $(p)$

\footnotetext{
${ }^{14}$ There is a richer tradition of work on abstract mass terms in the philosophical literature, however. See, for example, Sellars 1967.

15 The relevant modifications, as well as further justification for the mereological treatment we propose, are discussed in $\S 4.5$.
} 
Clearly, combining $\alpha$ with an expression denoting an individual $a$ yields the proposition $\operatorname{strength}(a)$, which says that $a$ is a portion of strength, not that $a$ is strong (viz., Kim is strength versus Kim is strong). We propose that a natural semantic alternative to direct predication is relating the individual $a$ to the denotation of $\alpha$, by a binary relation, and that the most natural binary relation is the possessive relation. As mentioned above, viewing individuals as 'having' substances is common in philosophical jargon. While we do not wish to make any metaphysical or epistemological claims about the nature of substances, it seems intuitively clear why possession should be a privileged relation between individuals and substances. While substances can be construed as universals, which particular individuals EXEMPLIFY, they might also be considered as the things that MAKE UP individuals, that is, integral parts of individuals. Integral (or inalienable) parthood is very prototypically expressed as possession in natural languages. This is easily seen for English in examples like 38.

(38) a. A square has four corners.

b. John has a nose.

Possessive strategies are thus a reflection of the semantics of substance possession required to express PC predication with substance-denoting PC lexemes.

Since substances are conceived of as sets of portions, a natural definition of substance possession is the one in 39 (where the possessive relation is written as $\pi$ ). What it says, informally, is that an individual $a$ has a substance $P$ if and only if $a$ has some portion of $P$.

(39) Substance POSSESSION: For any individual $a$ and substance $P, a$ has $P$ iff $\exists p[P(p) \& \pi(a, p)]$

A crucial aspect of PC predication that any theory must capture is its well-known context sensitivity (see e.g. Kennedy 2007 for a summary). Thus, a sentence like 40 can vary in truth value, depending on what standard one is using to evaluate tallness.

(40) Felicia is tall.

The sentence can be true in some contexts, false in others, and in yet other contexts its truth value may be indeterminable. For example, is 40 true when Felicia is five feet tall? In some contexts yes, in other contexts no, and in other contexts we simply are not certain. This context dependence is presumably universal and holds also for languages in which PC predication is expressed as substance possession, as demonstrated for Ulwa by the data in 41 , which show that the extent to which yûhka 'tall' can be truly attributed to Sherwell depends on the context in which he is considered.

(41) Sherwell ya bikiska balna karak laih yûhka katka muih almuk balna Sherwell the child PL with TOP tall.KA but person old.man PL karak laih yûhka sa. with TOP tall.KA NEG

'Sherwell is tall compared to children, but compared to old men he is not tall.'

(Jan11-2)

In the literature on adjectives discussed in $\S 5$, context sensitivity is dealt with in various ways, for example, by invoking contextually salient degrees on a scale, or partial functions and supervaluations. So far, our theory of substances and of substance possession does not accommodate context dependence in any way. Any individual either does or does not bear the relation $\pi$ to (a portion of) the substance $P$. Of course, it is possible to insist that the relation $\pi$ is in fact gradable, and that an individual can bear $\pi$ to a substance to a certain degree. But such a move seems counterintuitive and empiri- 
cally unmotivated. The oddity of data like 42 , for example, indicates that the possessive relation, at least as holds between two simple individuals, is not gradable.

(42) \#John has a nose more than Mary (does).

However, it is precisely to deal with context dependence, and with the concomitant issue of comparison, that we introduced the ordering relation $\leq$ on portions in the previous section. This order can be used to replicate in the domain of substances the effect of contextual standards. Since the semantics of substance possession is constructed as involving existential quantification over portions, context sensitivity can naturally be introduced as contextual domain restriction.

It is widely known that quantification in natural language is very often, if not always, restricted, and that the restriction is often contextually determined (Westerståhl 1984, von Fintel 1994, Roberts 1995, Cooper 1996, Gawron 1996, inter alia). For example, in most utterance contexts, 43 would not be understood to make a statement about everything in the domain of quantification, but rather about everything in a contextually salient subset of this domain.

(43) Everything is in the car.

We propose to incorporate context sensitivity as a contextual domain restriction on the existential quantifier over portions in the semantics of substance possession.

Informally, the idea is that only portions that are, in a sense, 'big enough' count as relevant in evaluating whether an individual has a substance (cf. what Kennedy 2007 calls the 'stand out' relation). That is, in asserting that there is a portion of a substance $P$ that an individual has, quantification is restricted to those portions that are ranked high enough by the preorder $\leq$. This kind of restriction seems to be a general property of sentences involving quantification over mass terms. For example, in many contexts, an utterance of $44 \mathrm{a}$ would be considered false if uttered by someone who has two pennies in her pocket and no other monetary possessions. Similarly, 44b, discussed in Travis 1989:18-19, would in many contexts be considered false if there is in fact no milk in the refrigerator save for two drops in the bottom of a drawer. In both cases, the relevant material (money, milk) must exceed a certain contextually determined amount in order to 'count' as verifying the sentence.

(44) a. I have money.

b. There is milk in the refrigerator.

A similar kind of contextually sensitive domain restriction is found with other cases of quantification over ordered domains, such as modality. Following advances in modal logic made in the early twentieth century, it has been common since Kratzer's work (Kratzer 1977, 1991) to view epistemic possibility modals such as might in 45 as quantifiers over possibilia (usually modeled in terms of possible worlds).

(45) Felicia might be dead.

Example 45 might be analyzed as asserting that a possibility (e.g. a possible world) exists in which Felicia is dead. As Kratzer has emphasized, however, only reasonably nonremote possibilities count. For example, a hearer who has seen Felicia sitting in the next room a minute ago is likely to consider an utterance of 45 false, even though a very remote possibility that, by some extremely unlikely accident, she has in fact died in the minute that has passed cannot be ruled out. ${ }^{16}$ What this suggests is that, when ordered

\footnotetext{
${ }^{16}$ In Kratzer's and much subsequent work, this kind of domain restriction is done by means of a contextually determined 'ordering source'.
} 
domains are involved, it is very common to find exactly the kind of contextual restriction to elements 'high enough' in the order that we posit for quantification of possessed portions of substances.

To illustrate how domain restriction can be utilized to model context dependence, we turn now to a compositional analysis of PC constructions in Ulwa, beginning with an analysis of predicative constructions in $\S 4.3 .{ }^{17}$ The same mechanism of domain restriction at work in modeling the context sensitivity of predicative PC constructions is also used to model comparison and comparative PC constructions; we extend the analysis developed for Ulwa predicative constructions to Ulwa comparatives in $\$ 4.4$.

4.3. Predicative Constructions In UlWa. Ulwa predicative PC constructions have the form in 26, repeated in 46.

(46) Yang as-ki-na minisih-ka.

1sG shirt-1sg dirty-3sG.POSs

'My shirt is dirty.'

As discussed in $\S 2$, Ulwa PC words are constructed from a root and the possessive suffix $-k a$, which also marks the possessed noun in a possessive NP. We take PC roots in Ulwa to denote substances in the sense elaborated above. Consistent with our usage so far, $P, Q$ are used as variables over such substances, and English nominalizations in boldface as substance constants. For example, the substance denoted by the Ulwa root minisih- 'dirty' is written as dirtiness, as in $47 .{ }^{18}$

(47) $\llbracket$ minisih $\rrbracket=$ dirtiness $\subseteq \mathcal{A}$

The denotation we propose for the suffix $-k a$ is in 48 .

(48) $\llbracket-\mathrm{ka} \rrbracket=\lambda P \lambda x \lambda D . \exists^{D} z[P(z) \& \pi(x, z)]$

In $48, D$ is a variable over sets of portions. ${ }^{19}$ The notation $\exists^{D}$ is used to express restriction of the existential quantifier only to elements of $D$. Denotation 48 says that $-k a$ takes a substance $P$ and an individual $x$ and returns a context-dependent proposition (technically, a function from sets of portions to truth values). Given some set of portions - call it $\mathbf{d}$-the proposition expressed is that there is a portion of $P$ that $x$ has, and that that portion belongs to $\mathbf{d}$.

The denotation of an Ulwa word like minisihka 'dirty' is straightforwardly derived from the meaning of $-k a$ and the meaning of the root by function application, as in 49 .

(49) $\llbracket$ minisihka $\rrbracket=\lambda x \lambda D \cdot \exists z^{D}[\operatorname{dirtiness}(z) \& \pi(x, z)]$

The denotation of a PC word with $-k a$ might be called a context-sensitive predicate - a function from individuals and sets of portions to propositions. Combining such a PC word with an individual-denoting term such as a proper name does not itself determine a proposition. Rather, in order to do so, the context must supply a domain restriction for the existential quantifier over portions. ${ }^{20}$

\footnotetext{
${ }^{17}$ Ulwa was chosen simply because it is the language the possessive strategy of which we understand best. Extension to other languages must be left for future research.

${ }^{18}$ As above, this is purely a notational convention, not a theoretical claim about nominalization in English.

${ }^{19}$ We take portions to be a sort of individual, that is, a subtype of type $e$, the type of simple individuals.

${ }^{20}$ Since our motivation for assuming a possessive strategy for Ulwa is the fact that $-k a$ is used in nominal possession, the question arises of how the denotation of $-k a$ in 48 relates to that of $-k a$ in nominal possession. Koontz-Garboden \& Francez 2010 discusses this issue in detail, within a logical form (LF-)style analysis of the syntax-semantics interface (inspired by Barker 1995). For various reasons, we do not endorse this style of analysis here, and prefer an analysis of possessive NPs as generalized quantifiers (see e.g. Barker 2002, Peters \& Westerståhl 2006, Francez 2009 for discussion). The details of such an analysis are too complex to present here and are largely irrelevant to our concerns. In (i) we therefore simply give the two denotations we
} 
One final note is due regarding the nature of the contextually supplied sets that form the restriction for the existential quantification over portions in the meaning of $-k a$. In order to ensure that this semantics is coherent, and in particular that it extends coherently to comparatives, the range of possible values for $D$ must be constrained so as to only include subsets of a substance $P$ that are contiguous intervals right-bounded only by the supremum of $P$ if there is one. In other words, ones that include all and only the portions of a substance that are either at or exceed a certain cut-off point in the preorder induced by $\leq$. To achieve this, we restrict the possible values of $D$ to sets of portions that form a left-bounded interval of a substance, as defined in 50 .

(50) Interval: For any substance $P$, a set of portions $D \subset P$ forms a left-bounded interval iff $\exists p \in P: \mathrm{D}=\{q: p \leq q\}$.

To see why this constraint is required, imagine that there are only three portions of some substance — say, beauty - ordered as in 51 .

(51) $\left\{p_{0} \leq p_{1} \leq p_{2}\right\}$

Now, suppose that Keats has portion $p_{0}$ and Yates has portion $p_{2}$. Then, intuitively, if Keats is beautiful, then certainly so is Yates. But if contextual domains are not intervals, this does not come out as an entailment on our semantics. Suppose that the contextual domain $D$ of portions such that having a portion in that domain makes one beautiful is $D=$ $\left\{p_{0}, p_{1}\right\}$. Then Keats has a portion in $D$ but Yates does not, which, on our semantics, makes Keats beautiful and Yates not, counterintuitively. The restriction of values of $D$ to subsets of a substance conforming to 50 prevents this problem. Having determined a possessive semantics for Ulwa predicative constructions, we now turn to comparatives.

4.4. Comparatives In Ulwa. As discussed earlier, Ulwa comparatives involve the use of possessive - $k a$ in addition to the comparative lexeme kanas 'more'. An example is given in 52 .

(52) Abanel ya kanas yûh-ka Clementina karak.

Abanel the more tall-3sG.Poss Clementina with

'Abanel is taller than Clementina.'

(Jan11-14)

The intuition behind our analysis of the Ulwa comparative is that 52 expresses the proposition that Abanel's maximal portion of height outranks Clementina's maximal portion of height by the ordering $\leq$. The role of kanas is to introduce a comparison between these two portions. Formally, this is done indirectly by way of comparing the domains restricting the quantification over portions possessed by the target and the standard. For the analysis to work, we need to make the straightforward assumption that any individual who has a substance has a maximal portion of this substance. ${ }^{21}$ Formally, this means that the set of an individual's portions of any substance $P$ has a supremum. ${ }^{22}$

propose for the two uses of $-k a$. The two differ combinatorically, as necessitated by their different syntactic distributions. The crucial point is that the lexical semantic core of $-k a$, the contribution it makes to truth conditions, is identical in both uses. The relevant part of the denotation is underlined in (i).

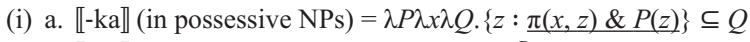

b. $\llbracket-k a \rrbracket$ (in PC constructions) $=\lambda P \lambda x \lambda D \cdot \exists^{D} z[\pi(x, z) \& P(z)]$

${ }^{21}$ In degree-based theories of comparatives, the equivalent of this assumption is that any individual who has a degree on a scale has a maximal degree on the scale. See $\S 4.5$ for further comparison of our substancebased theory and degree-based theories.

${ }^{22}$ There is a clear connection between the supremum of the set of an individual's portions of a property and Moltmann's (2009) notion of a trope. Consequently, our treatment of gradability and comparison bears an obvious affinity to hers. See $\S 4.5$ for more on the affinities between our analysis and Moltmann's. 
This is added as the postulate $\mathrm{P} 3$ in 53 , where $\Pi_{a}^{P}$ is the set of portions of $P$ that an individual $a$ has if there is one.

(53) P3: For any individual $a$ and substance $P$, if $\Pi_{a}^{P} \neq \varnothing$, then $\Pi_{a}^{P}$ has a supremum. Recall that the domains quantified over in the semantics of substance possession are restricted to intervals, as defined in $§ 4.3$. Therefore, given P3, Abanel's maximal portion of tallness can outrank Clementina's if and only if the set of domains containing portions of tallness possessed by Abanel is a proper superset of the set of domains containing a portion of tallness possessed by Clementina. ${ }^{23}$ This is because there is at least one domain, the one containing all portions of tallness bigger than or equal to Abanel's maximal portion, that does not contain any portions of Clementina's.

We exemplify the formal analysis by showing the compositional derivation of 52 . The denotation we propose for kanas 'more' is given in 54 (where $\alpha$ is a variable over the type of PC words in $-k a$ ).

(54) $\llbracket \mathrm{kanas} \rrbracket=\lambda \alpha \lambda x \lambda y . \alpha(y) \subset \alpha(x)$

Kanas combines first with a PC word, returning a relation between individuals. Combining kanas with yûh-ka 'tall' yields the relation in 55 .

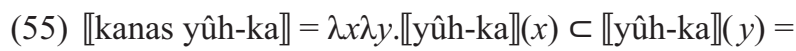
$\lambda x \lambda y \cdot\left(\lambda u \lambda D . \exists z^{D}[\operatorname{tallness}(z) \& \pi(u, z)]\right)(x) \subset$ $\left(\lambda u \lambda D . \exists z^{D}[\operatorname{tallness}(z) \& \pi(u, z)]\right)(y)=$ $\lambda x \lambda y .\left\{D: \exists z^{D}[\operatorname{tallness}(z) \& \pi(x, z)]\right\} \subset\left\{D: \exists z^{D}[\operatorname{tallness}(z) \& \pi(y, z)]\right\}$

As discussed above, this relation holds between two individuals $x, y$ if and only if the set of domains, or intervals, of tallness in which $y$ has a portion is a strict superset of the set of domains in which $x$ does. This is the case if and only if $y$ is taller than $x$, as illustrated pictorially in 56. In this picture, the dotted lines are the domains in which $x$ has a portion. The dashed lines are domains in which $y$ has a portion but $x$ does not. The solid line is the set of all portions of tallness ordered by $\leq$.

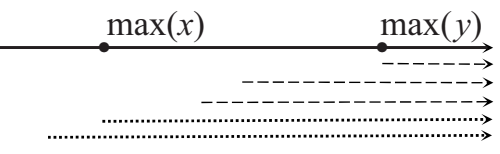

We take the denotation of the standard prepositional phrase to be simply that of the nominal complement of the preposition karak 'with'. ${ }^{24}$ Thus, the target and standard phrase both contribute individuals. Combining 56 with these individual denotations in order (standard first, then target, consistent with the syntax in 58) yields the final meaning of 52 in 57.

${ }^{23}$ Here is a simple proof of this. Let $a, b$ be individuals and $P$ a substance. Let $\Pi_{a}^{P}$ be the (nonempty) set of portions of $P$ that $a$ has, and similarly for $\Pi_{b}^{P}$. Let $D_{a}$ be the set of domains that contain an element of $\Pi_{a}^{P}$, and similarly for $D_{b}$. Let $M A X_{a}$ be the supremum of $\Pi_{a}^{P}$, and similarly for $M A X_{b}$. We want to prove (i).

(i) $D_{a} \subset D_{b} \Leftrightarrow M A X_{a}<M A X_{b}$

Suppose the right-hand side is false. Then $M A X_{a} \geq M A X_{b}$. Let $D \in D_{b}$. By interval, $\exists p: D=\{q: p \leq q\}$. By definition of $D_{b}, p \leq M A X_{b}$. Therefore, $p \leq M A X_{a}$. Therefore, $M A X_{a} \in D$, and therefore $D \in D_{a}$. So we get that whenever $D \in D_{b}, D \in D_{a}$, contrary to the left-hand side $D_{a} \subset D_{b}$. This proves one direction. For the other direction, suppose that the left-hand side is false. Then $D_{b} \subseteq D_{a}$. Let $D \in D_{b}$. Then, by definition of $D_{b}$ and interval, $\exists p \in \Pi_{b}^{P}, D=\{q: p \leq q\}$. Suppose $p=M A X_{b}$, then for any element $q \in D, q \geq M A X_{b}$. Since, by assumption, $D_{b} \subseteq D_{a}$, and $D \in D_{b}$, then $D \in D_{a}$. Hence, $\exists q \in \Pi_{a}^{P}: q \geq M A X_{b}$, contrary to the right-hand side $M A X_{a}<M A X_{b}$. QED

${ }^{24}$ Our treatment of the target preposition phrase as entity-denoting, essentially denying that there is any semantic contribution by the 'than' (in this case karak) particle, is consistent with general practice in the literature (see e.g. Kennedy 2007). 
(57) $\llbracket(52) \rrbracket=1$ iff

$\left\{D: \exists z^{D}[\operatorname{tallness}(z) \& \pi(\right.$ Clementina, $\left.z)]\right\} \subset$

$\left\{D: \exists z^{D}[\operatorname{tallness}(z) \& \pi(\right.$ Abanel, $\left.z)]\right\}$

For completeness, the syntactic structure we assume for 52 is given in $58 .^{25}$

(58)

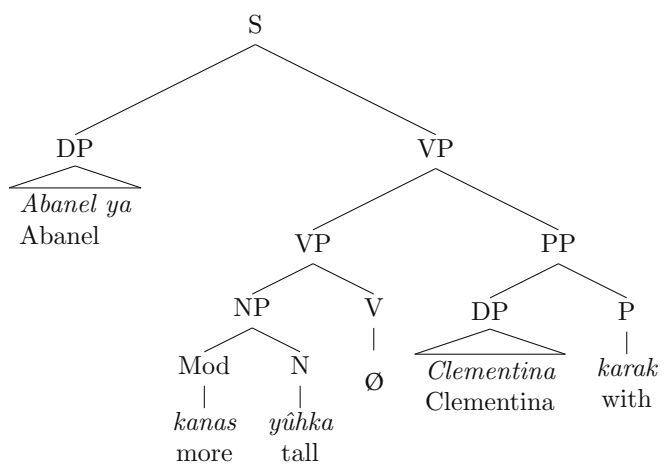

The example in 52 is a simple phrasal comparative in which the standard and target phrases are proper names. While Ulwa does not have clausal comparatives, it does have phrasal comparatives in which the standard phrase is an internally headed relative clause (a structure robustly attested in the grammar of Ulwa and Misumalpan generally—see Alpher \& Hale n.d., Green 1992, Koontz-Garboden \& Francez 2010). These are exemplified by the data in 59 .

(59) a. Û-ma ya kanas sik-ka ka wak dai karak.

house-2sG the more big-3SG.POSS SENT.KA other PST with

'Your house is bigger than the other was.'

b. Sirihîring-ma ya kanas yam-ka ka pumting dai speedboat-2sG.POSS the more good-3sG.POSS SENT.KA think.1SG.PRF PST ya karak.

the with

'Your speedboat is better than I thought.'

(Jan11-26)

These examples, like their translational English counterparts, cannot be analyzed in the same way as 52, since they do not compare individuals but rather portions (or degrees). Intuitively, while 52 compares Clementina and Abanel for height, 59b compares the maximal portion of goodness that your speedboat has to the maximal portion of goodness I thought it had (i.e. the maximal portion it has in all of my belief worlds). In the literature on comparatives (see Kennedy 2006 for an overview), English examples of this kind are often treated as involving abstract syntax, with the comparative morpheme -er taking scope over two clauses. The standard phrase is taken, following Bresnan (1973), to involve obligatory deletion of a predicate identical to the matrix predicate. Regardless of whether such a syntax is correct for the relevant Ulwa examples, it is

\footnotetext{
${ }^{25}$ We believe that this syntax is well motivated, but since the focus of this article is not the syntactic structure of comparatives, we do not dwell on it in detail here. We have included a null V in 58, since the copula is null in the third person but not in other persons (see e.g. the discussion and data in Koontz-Garboden 2009a). We treat the target phrase syntactically as a modifier. This choice is motivated by its free order with respect to the other constituents; it can appear sentence-initially, after the subject DP, or finally, as it does in 52. The prosodically unmarked position for it is sentence-final, as in 52 and in the structure in 58. That kanas yûhka 'more tall' is a constituent is suggested by the fact that it is never split up by target or standard material.
} 
clear that their interpretation is similar to the one assumed for similar English examples, and involves a meaning for kanas that scopes over two clausal meanings. ${ }^{26}$

Such a meaning for kanas is given in 60 , where $P$ and $Q$ are variables over sets of domains.

$$
\text { (60) } \llbracket \mathrm{kanas} \rrbracket=\lambda Q \lambda P . Q \subset P
$$

The derivation of $59 \mathrm{~b}$ is then as follows. The target phrase pumting dai ya karak (literally, 'with the I thought') is interpreted as involving obligatory deletion of the matrix material Sirihîring-ma ya yam-ka 'your speedboat is good', to produce the meaning in 61 .

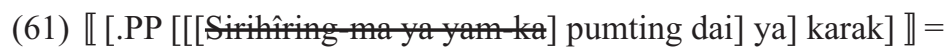
$\lambda D$. I thought: $\exists^{D} z[\operatorname{good}(z) \& \pi($ your-speedboat, $z)]$

The matrix clause is interpreted by function application in the obvious way, yielding 62 .

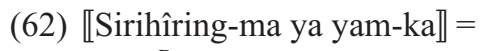
$\lambda D . \exists^{D} z^{\prime}\left[\operatorname{good}\left(z^{\prime}\right) \& \pi\left(\right.\right.$ your-speedboat, $\left.\left.z^{\prime}\right)\right]$

These two denotations form the arguments for kanas, yielding 63 as the meaning of $59 \mathrm{~b}$.

(63) $\lambda D . \exists^{D} z^{\prime}\left[\operatorname{good}\left(z^{\prime}\right) \& \pi\left(\right.\right.$ your-speedboat, $\left.\left.z^{\prime}\right)\right] \subset$

$\lambda D$. I thought: $\exists^{D} z[\operatorname{good}(z) \& \pi($ your-speedboat, $z)]$

According to $63,59 \mathrm{~b}$ is true just in case the set of domains that contain a portion of goodness that your speedboat possesses is a proper subset of the set of domains containing a portion that I thought your speedboat possesses, which is the case exactly when the maximal portion of goodness your boat has in my belief worlds is smaller than the maximal portion it actually has.

The overarching point of this section has been that modeling substance possession in terms of existential quantification over domains of portions allows us to handle both predicative and comparative PC constructions in Ulwa, capturing the fact that the former are context-sensitive in a way that the latter are not. An important and, we believe, highly desirable feature of this analysis is that the meaning of the comparative form is built compositionally on the meaning of the positive form, exactly as one would expect, given that the former is syntactically built from the latter by addition of kanas. We elaborate on this point further in $\S 5$.

4.5. Substances AND SCALEs. Our explanation for why possessive PC constructions are possessive relies on the assumption that the PC lexemes that appear in such constructions denote substances. Substances are not standardly evoked in the semantic literature on PC constructions, which is concentrated on adjectives and employs instead an ontology of scales, conceived of as a totally ordered set of points, generally called degrees (see Kennedy 1999:97, 188 for discussion). It is therefore pertinent to examine the exact relation between substances and scales, determining in what ways, if any, they differ, and whether our analysis of the variation found in PC constructions depends in any way on choosing between them. In the following, we discuss this issue, showing that substances and scales do in fact have distinguishing properties, but that none of them are relevant for the analysis of possessive PC constructions. The distinction between substance-denoting and adjectivally denoting PC lexemes could equally well be stated in terms of scales. Nevertheless, the model-theoretic differences between the

\footnotetext{
${ }^{26}$ In the literature, phrasal comparatives like the ones analyzed earlier are sometimes reduced to this kind of case, so as to provide a uniform semantics for degree modifiers like more and kanas. See, for example, Pancheva 2006, Bhatt \& Takahashi 2007, and Hofstetter 2012 for discussion. We leave open here the question of whether this is desirable for Ulwa.
} 
two, which are related to the orderings involved, have potential empirical consequences that we feel motivate the use of substances. Both substances and scales are ordered sets, and the relation between them is completely determined, and also easily obscured, by the different orderings involved. We consider first how scales and substances differ with respect to these ordering relations. We then discuss the kinds of data that we believe do motivate our adoption of a substance-based theory over a scale-based theory. ${ }^{27}$

ORDER-THEORETIC DIFFERENCES BETWEEN SUBSTANCES AND SCALES. Two orderings were invoked in the analysis of substances above. The first is the mereological order $\preceq$; the second is the 'size' ordering $\leq .^{28}$

The first difference between substances and scales is in the 'size' ordering $\leq$. In our definition of substances, $\leq$ is a total preorder on portions. It is an essential property of scales that they are totally ordered, rather than preordered. The difference between an order and a preorder is that the former is antisymmetric and the latter not. The ordering relation on degrees on a scale is, by definition, antisymmetric. That is, if two degrees $d_{1}$, $d_{2}$ are such that they occupy the same place in the ordering $\left(d_{1} \leq d_{2}\right.$ and $\left.d_{2} \leq d_{1}\right)$, they are the same degree. Giving up antisymmetry for substances has exactly one consequence, namely, that two distinct portions of a substance can occupy the same position in the ordering (intuitively, be of the same 'size') without being the same portion. While this is a substantive difference between substances and scales, it does not play any role in our analysis of PC constructions and hence is inconsequential to our theory of variation in PC constructions. The motivation for assuming that portions are preordered rather than ordered has to do with more general considerations about the behavior of mass nouns, which are discussed below.

The second difference between substances and scales is in mereological structure. In the tradition stemming from Parsons (1970) and Link (2002) and adopted here, the essential property of mass nouns such as water and oil is that the sets they denote are partially ordered by a transitive, reflexive, and antisymmetric ordering relation, $\preceq$, conceived of as a mereological part-whole relation. The ordering of degrees on a scale, in contrast, is not intended to be mereological. Degrees do not intuitively stand in a partwhole relation to one another; they cannot overlap and have parts in common. This is reflected formally by the fact that degrees are totally ordered. For any two distinct degrees $d_{1}$ and $d_{2}$, either $d_{1}$ precedes $d_{2}$, or vice versa, whereas two portions of water need not be parts of one another. However, it is easy to define mereological objects based on scales that behave like substances in the relevant respects. Any scale is uniquely correlated with a set of intervals over that scale (with points as a special case). ${ }^{29}$ Intervals on a scale can intuitively be partially ordered by a part-whole relation $\preceq$, and can form

\footnotetext{
${ }^{27}$ One key motivation for scales provided in the literature that we do not believe distinguishes scales from substances is scalar typology of the kind documented for adjectives by Kennedy and McNally $(1999,2005)$ and Rotstein and Winter (2004). Certain English adjectives, such as pure, are taken to have closed scales, that is, scales that have an upper limit, a maximal degree. For example, pure cocaine cannot become any purer than it already is. So far as we can see, such generalizations, to the degree that these hold for possessive PC constructions (a question that requires empirical investigation), can be captured in terms of substances. The difference between open and closed scales can be modeled by distinguishing between bounded and unbounded substances, where the former have a set of maximal elements (and possibly a supremum) whereas the latter do not. We leave a detailed exploration of this issue for future research.

${ }^{28}$ In the literature on mass nouns, mass denotations have not traditionally been associated with any ordering beyond the mereological part-of relation, but this is not for any principled reason.

${ }^{29}$ For any two points $a$ and $b$ on a scale such that $a \leq b$, an interval is the set of points $x$ satisfying $a \leq x \leq b$.
} 
parts of other intervals, overlap, and so forth. ${ }^{30}$ Thus, any properties of substances related to their mereological structure could be recreated in terms of sets of intervals on a scale. In any case, the fact that substances have mereological structure plays no role in our argument. The relation $\preceq$ is completely inert in our analysis of PC constructions. The reasons for assuming that the lexemes participating in possessive PC constructions have mass denotations is that these lexemes are mass nouns in many languages, discussed further below.

The conclusion of this discussion is that the formal properties that distinguish substances from scales do not bear in any way on the main argument of this article. The distinction we propose between the two kinds of PC lexemes can equally well be stated using scales, without affecting the explanation of variation between possessive and canonical PC constructions. A translation of our theory into one based on a scalar ontology could be constructed along the following lines. ${ }^{31}$ What we call substance-denoting PC lexemes are recast as scale-denoting PC lexemes. Adjectivally denoting PC lexemes then differ from scale-denoting ones in that they do not denote scales, but something else. This is in accord with the semantic literature on adjectives, where it is never assumed that they denote scales, though what they do denote is a matter of controversy, as discussed in $§ 5$. Possession plays the same role it does in our substance-based analysis, namely that of contributing a relation between individuals to scales. For example, an individual can be related to a scale by possessing a degree or an interval on that scale. ${ }^{32}$ In fact, on one common analysis of adjectives going back to Cresswell 1977, they denote relations between individuals and degrees on a scale that hold if and only if the individual has the degree. On such a relational analysis, adjectives can be taken to encode lexically the meaning that is reached by combining a scale-denoting PC lexeme with possessive morphosyntax. This essentially recreates our analysis of the observed variation between possessive and canonical PC constructions, pinpointing it again on the lexical semantics of PC lexemes. Adjectivally denoting lexemes lexically encode what can only be achieved compositionally with scale-denoting ones. We take no stance on the desirability of such an analysis for English adjectives, and more generally on whether the denotation of adjectivally denoting PC lexemes should be identified, in at least some languages, with the denotation reached by composing substance-denoting lexemes with possessive morphology. We point it out only to show that a reasonably concrete proposal for replacing substances with scales leaves our core intuition about variation unchanged.

Notwithstanding our belief expressed above that a scale-based analysis can capture the core intuitions from above, as mentioned earlier, there are other, independent empirical considerations that we believe motivate our choice to associate possessive predicating PC lexemes with substances. These are discussed briefly in the following two subsections.

Mereology. The first motivation for invoking an ontology of substances instead of scales is that, in many languages, $\mathrm{PC}$ lexemes that give rise to possessive $\mathrm{PC}$ constructions are mass nouns. ${ }^{33}$ For example, at least one of the possessive constructions in

\footnotetext{
${ }^{30}$ In fact, it has been argued that intervals should replace degrees in the analysis of comparatives, for example, by Kennedy (2001) and Schwarzschild and Wilkinson (2002).

${ }^{31}$ We thank an anonymous referee for pointing out the possibility of such an approach.

32 Such a version of this analysis has recently been proposed in Bochnak 2013:112ff. for the Bantu language Luganda.

${ }^{33}$ Prompted by a comment from a referee, we stress here what we view as the status of such ontological commitments as the commitment to substances. By invoking substances, we are making claims about what is required of a formal model of meaning in natural language. We are not thereby committing ourselves to any
} 
which the Hausa PC nominals described earlier are used is restricted to mass and plural nouns (Abdoulaye 2006:1139-40). Similarly, in Huave (see n. 6) the possessive construction used in possessive PC predication otherwise only allows mass nouns (Kim \& Koontz-Garboden 2013:14). In Basaá (briefly discussed in §2.5), possessive predicating PC words pattern with mass nouns in not inflecting for number (Jenks et al. 2013). Finally, in English and other familiar Romance and Germanic languages, the PC nouns that participate in possessive PC predication are always mass nouns. It is only natural to assign such nouns mass denotations, on a par with other mass nouns. ${ }^{34}$ As mentioned above, scales can also be associated systematically with mass-like structures, namely sets of intervals. As far as we can see, such sets would do equally well in capturing the affinity between possessive predicating PC lexemes and other mass nouns, even if the semantics of mass nouns is more standardly framed in terms of substances.

ANTISYMMETRY. The motivation for giving up antisymmetry in modeling possessive predicating PC lexemes comes from considerations about the semantics of English abstract mass nouns such as beauty and strength. To the degree that English has possessive PC constructions, they feature such mass nouns, and we therefore believe it is desirable for a semantic theory of possessive predicating PC lexemes that it be at least compatible with their semantic properties. One such property has to do with the relation between gradability/comparison and identity conditions. There is a strong intuition, modeled explicitly in the philosophical literature, especially Moltmann 2009, that attributes have unique manifestations in individuals. In that literature, such unique manifestations are called tropes, and their identity conditions are determined by their bearers (the manifesting individuals), independently of gradability and comparison. For example, the particular entity that is Kim's strength is not identical to the particular entity that is Sandy's strength, even if Kim and Sandy are as strong as one another. In Moltmann's theory, phrases like Kim's strength are names of tropes. The counterparts of tropes in our terminology are portions of substances. ${ }^{35}$ The intuition that two individuals who are equally strong nevertheless have distinct portions of strength is naturally captured if portions of substances are preordered, since two portions of a substance can occupy the same place in an ordering without being identical. This intuition might have linguistic manifestation in sentences such as 64 .

(64) The Taj Mahal has as much beauty as the Stata Center, though their beauties are very different.

It is difficult to see how to assign truth conditions to 64 that do not require the Taj Mahal and the Stata Center to have the same degree of beauty, while having different beauties. This would be impossible to do if the noun beauty were taken to denote the scale of beauty, and a noun phrase like the Taj Mahal's beauty the Taj Mahal's degree of beauty. In that case, 64 would come out saying that the two buildings have the same de-

claims about metaphysics or ontology in the philosophical sense, which are claims about the world, not about grammatical models. Emmon Bach (1986) famously drew the distinction between NATURAL LANGUAGE METAPHYSICS and METAPHYSICS. If anything, we are engaged in the former, and draw no conclusions about any relation to the latter.

34 There is also an empirical argument from Ulwa for mereological structure in the denotation of PC lexemes, though this has to do with the morphosyntax and semantics of possession, and nothing to do with mass/ count diagnostics. The argument is too involved to discuss here; we refer the reader to Francez \& KoontzGarboden 2015 for discussion.

${ }^{35}$ In fact, our possessive relation seems closely related to the relation $B$ assumed by Moltmann (2009:69) to hold between a trope and its bearer. 
gree of beauty but their degrees of beauty are different. This is a contradiction and clearly not what 64 means. If, however, a noun like beauty is taken to denote a set of preordered portions, then 64 can be taken to say that the two buildings have different portions of beauty that nevertheless occupy the same position in the preorder. ${ }^{36}$

In sum, we have argued that although all key observations made above about PC constructions could be recast in a scale-based theory, there are independent reasons to do with mereological structure and the size preordering that seem to us to warrant, if weakly, a substance-based theory like the one discussed here. These considerations, however, are entirely tangential to the main points of the article. ${ }^{37}$

5. THE CASE FOR LEXICAL SEMANTIC VARIATION. Some of the principal explananda of generative linguistics are systematic patterns of surface variation between expressions that are taken to be truth-conditionally equivalent. ${ }^{38}$ The analytical question explored about such variation in the literature is what aspects of grammar are responsible for it. One option is that the variation is due entirely to syntactic factors. For example, two constructions that are truth-conditionally equivalent but are morphosyntactically different from one another might be different for reasons that have to do with variation in

\footnotetext{
${ }^{36}$ A referee suggests that on some conceptions in the literature, the relation ordering degrees on a scale is also not viewed as antisymmetric. The referee points to the following remark from Cresswell (1977:266), in which he cites Wheeler: 'The > is heuristic, in order to suggest the direction of the comparison. It is tempting to think of $>$ as at least a partial ordering (i.e., a transitive and antisymmetric relation); whether it should be strict or not or total or not seems unimportant, and perhaps we should even be liberal enough not to insist on transitivity and antisymmetry (Wheeler, 1972, p. 319)'. Cresswell's discussion is in fact purposefully vague and hedgy on precisely this issue. Moreover, as he explicitly says, his $>$ is a hypothesized empirical relation on individuals in the world, not an ordering on degrees, and in any case is not meant to be a relation that is part of the modeltheoretic semantic account of any linguistic expressions, an account that he purposefully avoids giving. However, Creswell's intuition is made explicit in Bale 2011, and so we briefly discuss that theory.

In fact, Bale does assume that scales are strictly ordered and hence are antisymmetric (see Bale 2011: 176-77). In his theory of adjectives (which we find very attractive), the meaning of an adjective is built from a primary scale, which is a scale of equivalence classes of individuals. The scale is formed based on a connected preorder on individuals, for example, the preorder 'has as much beauty as'; Bale shows how one can construct a scale based on this preorder by linearly ordering the equivalence classes. He then derives the meaning of adjectives based on a mapping between such a linear order and a universal scale, which is also a strict order. Our substances are thus similar to Bale's primary scales in being preordered, but differ in that they relate portions rather than individuals. In other words, where Bale has the relation ' $\mathrm{x}$ has as much beauty as $y$ ' as a primary relation that figures in the meaning of adjectives, we have the predicate ' $p$ is a bigger portion of beauty than q' as a primary relation, and derive his primary relation ' $\mathrm{x}$ has as much beauty as y' compositionally.

Again, it is almost certain that one can replace our substances with Bale's preorders on individuals, or even

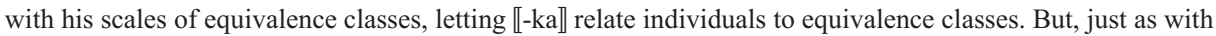
the scale-based alternative we sketch above, this has no bearing on the main point of the article, which is that there are two kinds of PC lexemes differing in denotation (regardless of the ontology one uses).

${ }^{37}$ An anonymous referee asks why, if one were to adopt a scale-based theory, 'possessive morphology in particular would be used to convert degree predicates into degree relations'. The answer to this, we think, is much as described already above: the PC lexemes on which possessive PC constructions are built denote sets of entities of a different sort from standard individuals (be it substances in our sense or sets of degrees), and these entities have to be related to individuals to get the right truth conditions, which, as we show, direct predication does not derive. As we discuss in some detail in $\$ 4.2$, possession is natural in PC constructions with substance-denoting PC lexemes simply because it has a very general meaning, it is generally used to relate entities to one another (whether John with the table he owns, the nose he has, etc.), and in particular because it is commonly used to express the relation between individuals and integral parts. The same considerations would apply if PC lexemes were scale-denoting rather than substance-denoting.

${ }^{38}$ Of course, it is difficult to show full truth-conditional equivalence across languages, as Keenan (1973) shows, but we make this simplifying assumption here.
} 
the nature of case-marking mechanisms that are semantically inconsequential. Alternatively, it could also be the case that the surface-level differences in morphosyntax are only apparent, and that at a deeper level the syntactic structures are identical, with these structures being obscured by the nature of the surface realization of functional heads. ${ }^{39}$ Another option is that the variation is rooted in semantic differences between the two constructions, either in variation in the mode of semantic composition and other functional elements or in the meaning of the semantic primitives. Talmy's $(1972,1985)$ analysis of variation in the structure of motion expressions is an example of exactly this kind, with verb-framed behavior driven by verbal lexicalization of manner-oriented meaning components in the verb, and satellite-framed behavior driven by lexicalization of path components to the exclusion of manner.

Our main argument is that the variation in the form of PC constructions we observe in this article - that is, the contrast between possessive and canonical ones - is of the second kind, rooted in lexical semantic variation in the domain of PC lexemes. Assuming that possessive and canonical PC constructions have the same truth conditions, the picture we argue for is summarized in 65 , repeated from 7 above. ${ }^{40}$

(65) The lexical semantic variation hypothesis: Substance-denoting PC lexemes require possessive semantics to achieve the truth conditions of $\mathrm{PC}$ constructions. Adjectivally denoting PC lexemes do not. Possessive morphosyntax contributes possessive semantics, and hence surfaces only with PC constructions built on substance-denoting PC lexemes.

A natural question to ask given this hypothesis is whether the range of data it is meant to explain can be explained equally well without the assumption of lexical semantic variation. Clearly, if it is possible to extend an existing theory of the semantics of adjectives to cover both types of PC lexemes we are positing, without losing generalizations, then doing so is preferable to positing variation (see e.g. discussion in Matthewson 2001). It is easy to show, however, that carrying the semantics of adjectives over to possessive predicating PC lexemes leads to wrong predictions, as well as to the loss of generalizations about possessive morphosyntax in PC constructions.

Equating the semantics of possessive predicating PC lexemes and of adjectives in a language like English is revealed to be patently absurd by the existence of minimal pairs such as 66 .

(66) a. Krishna is wisdom.

b. Krishna is wise.

Obviously, wise and wisdom do not mean the same thing, since $66 \mathrm{a}$ and $66 \mathrm{~b}$ do not. That wisdom is a substance-denoting lexeme in our sense is clear from the fact, mentioned earlier, that 67 is truth-conditionally equivalent to $66 \mathrm{~b}$.

(67) Krishna has wisdom.

However, the more interesting question is what happens in a language like Ulwa. In this language, minimal pairs like those in 66 do not obviously exist. ${ }^{41}$ The relevant paradigm of Ulwa is repeated for ease of reference in 68 .

\footnotetext{
${ }^{39}$ Hale and Keyser's (2002) analysis of argument structure configurations giving rise to verbs of varying morphological shapes with identical meanings can be read in this way. See Koontz-Garboden 2009c for discussion.

${ }^{40}$ As discussed in $\S 4.5$, replacing 'substance-denoting' with 'scale-denoting' in 65 would be inconsequential.

${ }^{41}$ Ulwa PC lexemes are bound roots, and generally cannot occur without - $k a$ suffixation in predicative position. See Koontz-Garboden \& Francez 2010:210-14.
} 
(68) a. yûh-

?

b. Kal-ka yûh-ka.

feet-3sG.POSs tall/long-3sG.POSS

'It has long feet.'

c. Abanel ya kanas yûh-ka Clementina karak.

Abanel the more tall/long-3sG.Poss Clementina with

'Abanel is taller than Clementina.'

(Green 2004:sûki)

(Jan11-14)

The hypothesis that Ulwa PC roots have the same meaning as adjectives thus becomes more plausible. In this case, however, morphosyntactic considerations clearly argue against it. In the following, we show that existing theories of adjectives fail to capture important generalizations when carried over to Ulwa roots. The important question here is what explains the distribution of $-k a$ in Ulwa PC constructions. More specifically, any theory of Ulwa PC constructions should answer the following questions:

(i) What is the role of the suffix present on the PC lexeme in Ulwa PC constructions?

(ii) Why is the suffix present in Ulwa PC constructions a possessive one?

Question (ii) is particularly important to answer in light of the observation, made throughout this article, that possessive morphosyntax in Ulwa is part of a nonaccidental, systematic, and robust pattern of PC predication and comparison across a diverse range of languages. Neither of these questions receives an answer on the assumption that Ulwa PC lexemes have the meanings of adjectives.

There are two competing analyses of the semantics of adjectives in the literature, which we call the VAGUE PREDICATE ANALYSIS and the POSITIVE OPERATOR ANALYSIS. We examine each in turn, showing that assuming it for Ulwa roots leads to a theory that fails to answer the questions above about the nature of the suffix $-k a$.

5.1. The vague PRedicate analysis. The vague predicate analysis (e.g. Kamp 1975 and Klein 1980) models adjectival meanings as partial functions that, in any given context, delineate the domain into a positive extension, a negative extension, and an extension gap. Different contexts determine different delineations. Comparatives are handled using supervaluations or quantification over contexts. The technical details of this kind of analysis are not important here. What matters is that on this analysis, adjectives denote properties of individuals, which are predicated of individuals in predicative PC constructions.

If Ulwa roots are taken instead to denote vague predicates, then their suffixed forms with $-k a$ must have the same denotation, since it is the vague predicate that, on the relevant theories, applies to an individual denoted (or quantified over) by the subject. Such an analysis thus obliterates the semantic role our analysis assigns to - $k a$ (i.e. contributing possessive semantics). Absent a semantic role, some auxiliary explanation for the occurrence of $-k a$ is required. Koontz-Garboden \& Francez 2010 points out that $-k a$ also plays the morphosyntactic role of turning bound roots into free-standing syntactic words. As also pointed out there, however, a theory on which this is the only role $-k a$ plays misses the generalization that the Ulwa pattern is an example of a possessive strategy of predication, which we have shown in $\$ 2$ to be a common and systematic strategy employed in the grammars of many languages. Thus, a vague predicate analysis of Ulwa roots leaves question (ii) posed above entirely unanswered.

5.2. Positive OPERATOR ANALYSES. The positive operator analysis was first proposed by Cresswell (1977), developed, elaborated, and integrated into modern generative 
grammar in the work of Kennedy (1999, 2007, inter alia), and assumed by many others following him. On this analysis, lexical adjectives have a denotation that requires composition with a degree operator in order to participate in PC constructions. In predicative PC constructions, this degree operator is called pos and is introduced either by a degree morpheme (e.g. von Stechow 1984, Kennedy 1999) or by a typeshift (Grano 2011). In comparative PC constructions, the degree operator is contributed by comparative morphology or syntax. The important feature of this analysis here is that the two degree operators, the positive and the comparative one, are in complementary distribution. That is, in any given PC construction, the lexical adjective composes with exactly one of these operators.

If Ulwa roots have the denotation posited for adjectives on this approach, ${ }^{42}$ an answer to question (i) above could be given, namely that $-k a$ is a degree morpheme, contributing the pos degree operator. However, this answer makes the prediction that $-k a$ should be in complementary distribution with the comparative morpheme kanas. This prediction is clearly false, as shown by 68c. Furthermore, this approach offers no answer to question (ii), and would not do so even if the analysis of $-k a$ as a degree morpheme did not make the aforementioned incorrect morphological prediction.

5.3. The CASE FOR SEMANTIC VARIATION. The conclusion from this discussion is that Ulwa roots cannot profitably be analyzed as having the lexical semantics of adjectives, on either of the two main approaches to what that lexical semantics is. On both approaches considered, the possessive nature of the suffix $-k a$ remains entirely unexplained. Further, the very presence of $-k a$ on PC lexemes is unexplained if roots have a vague predicate semantics, and given an incorrect explanation if $-k a$ is taken to be degree morphology, as required if $-k a$ is to have any semantic role on a theory in which roots denote what adjectives denote on the pos approach.

Our theory that roots denote substances, by contrast, affords a perfectly natural explanation both for the role of $-k a$ (contributing a semantics of substance possession) and for its possessive nature. A hypothetical theory whereby adjectives have substance denotations, however, cannot be correct, given data like 66. Adjectives (and presumably nonpossessive predicating PC words more generally), therefore, must have a kind of meaning different from that of possessive predicating PC lexemes. These considerations therefore point to the general conclusion that our lexical semantic variation hypothesis is correct; possessive predicating and nonpossessive predicating PC lexemes differ in their denotations in the manner described.

6. Concluding Remarks. This article began by introducing and describing a systematic pattern of surface morphosyntactic variation in the form of property concept constructions. The observation is that some such constructions surface as canonical predicative constructions, while others take the form of possessive constructions. The range of possessive structures used to express PC predication is wide, including 'have' verbs, comitative prepositions, nominal possessive marking, and existential constructions.

The main theoretical question of the article is what determines whether a PC construction is possessive or canonical. We proposed the lexical semantic variation hypothesis, according to which the variation is rooted in the lexical semantics of PC lexemes. Specifi-

\footnotetext{
42 There are at least two approaches to the denotation of adjectives within positive operator approaches. Kennedy (1999) assumes that adjectives denote measure functions. Cresswell (1977) assumes they denote relations between individuals and degrees on a scale. This difference is irrelevant to the discussion here.
} 
cally, we posit two classes of PC lexemes, substance-denoting and adjectivally denoting ones, and argue that possessive $\mathrm{PC}$ constructions are possessive because possession is semantically required for substance-denoting lexemes to achieve the truth conditions characterizing PC constructions. This hypothesis was explored through the development of a model-theoretic analysis of substance-denoting lexemes as having mass denotations, and an analysis of Ulwa PC constructions in which the context-sensitivity of gradable PC predication is modeled as contextually restricted quantification.

Research has only recently begun to inquire into the nature of semantic variation, and the scope of such variation is still largely unknown (see von Fintel \& Matthewson 2008 for an overview of the state of the art). If the lexical semantic variation hypothesis is correct, our analysis constitutes another example of a genuinely lexical semantic source for morphosyntactic variation, both language-internally and crosslinguistically, in the morphosyntactic expression of truth-conditionally equivalent propositions, of the kind documented by Talmy $(1972,1985)$. One of the contributions we hope to have made is a demonstration that examining morphosyntactic variation through the lens of a formal and constrained semantic theory enables the discovery, formulation, and corroboration of predictive hypotheses about the relation between meaning and morphosyntactic variation.

\section{REFERENCES}

Abdoulaye, Mahamane L. 2006. Existential and possessive predication in Hausa. Linguistics 44.1121-64.

Alpher, Barry, and Kenneth L. Hale. n.d. On relativization in Miskito. Sydney: University of Sydney, and Cambridge, MA: MIT, MS.

Aronoff, MARK. 1994. Morphology by itself. Cambridge, MA: MIT Press.

BACH, EMmon. 1986. Natural language metaphysics. Logic, Methodology and Philosophy of Science 7.573-95.

Bale, Alan Clinton. 2011. Scales and comparison classes. Natural Language Semantics 19.169-90.

Barker, Chris. 1995. Possessive descriptions. Stanford, CA: CSLI Publications.

BARKer, Chris. 2002. The dynamics of vagueness. Linguistics and Philosophy 25.1-36.

Bhatt, Rajesh, and Shoichi Takahashi. 2007. Direct comparisons: Resurrecting the direct analysis of phrasal comparatives. Proceedings of Semantics and Linguistic Theory (SALT) 17.19-36. Online: http://elanguage.net/journals/salt/article/view/17.19.

Bierwisch, Manfred. 1989. The semantics of gradation. Dimensional adjectives, ed. by Manfred Bierwisch and Ewald Lang, 71-261. Berlin: Springer.

Bochnak, Michael Ryan. 2013. Crosslinguistic variation in the semantics of comparatives. Chicago: University of Chicago dissertation.

BRESNAN, JoAn. 1973. Syntax of the comparative clause construction in English. Linguistic Inquiry 4.275-343.

COOPER, Robin. 1996. The role of situations in generalized quantifiers. The handbook of contemporary semantic theory, ed. by Shalom Lappin, 65-86. Oxford: Blackwell.

Cresswell, Max. 1977. The semantics of degree. Montague grammar, ed. by Barbara Partee, 261-92. London: Academic Press.

Dixon, R. M. W. 1982. Where have all the adjectives gone? And other essays in semantics and syntax. The Hague: Mouton.

Francez, Itamar. 2009. Quantification in possessives. Proceedings of Semantics and Linguistic Theory (SALT) 19.165-79. Online: http://elanguage.net/journals/salt/article /view/19.10.

Francez, ItAMAR, and ANDREW KoOnTZ-GARboden. 2010. The grammar of property possession. Paper presented at the Workshop on Adjectives and Relative Clauses, Venice, June 17, 2010.

Francez, ItAmar, and Andrew Koontz-Garboden. 2015. A note on possession and mereology in Ulwa property concept constructions. Natural Language and Linguistic Theory, Published online 28 July 2015. DOI: 10.1007/s11049-015-9299-3. 
GaWron, Jean Mark. 1996. Quantification, quantificational domains and dynamic logic. The handbook of contemporary semantic theory, ed. by Shalom Lappin, 247-67. Oxford: Blackwell.

Grano, Thomas. 2011. Mandarin hen and universal markedness in gradable adjectives. Natural Language and Linguistic Theory 30.513-65.

Green, Thomas. 1992. Covert clause structure in the Miskitu noun phrase. Cambridge, MA: MIT, Ms. Online: http://www.slaxicon.org/papers/miskdp/2003-02/.

Green, Thomas. 1999. A lexicographic study of Ulwa. Cambridge, MA: MIT dissertation.

Green, Thomas. 2004. Electronic version of dictionary in Green (1999). Unpublished raw XML.

Hale, Kenneth L., and Samuel Jay Keyser. 2002. Prolegomenon to a theory of argument structure. Cambridge, MA: MIT Press.

Hale, Kenneth L., and Danilo Salamanca. 2002. Theoretical and universal implications of certain verbal entries in dictionaries of the Misumalpan languages. Making dictionaries, ed. by William Frawley, Kenneth C. Hill, and Pamela Munro, 25-59. Berkeley, CA: University of California Press.

Heim, Irene. 1985. Notes on comparatives and related matters. Austin: University of Texas, Austin, MS.

Hofstetter, Stefan. 2012. Phrasal comparison in Turkish: Associating individuals with implicit degrees. Proceedings of Semantics of Under-represented Languages in the Americas (SULA) 6.319-35.

Husband, E. Matthew. 2010. On the compositional nature of stativity. East Lansing: Michigan State University dissertation.

JAGGar, Philip. 2001. Hausa. Amsterdam: John Benjamins.

Jenks, Peter; Andrew Koontz-Garboden; and Emmanuel-Moselly Makasso. 2013. The lexical category and lexical semantics of property concept words in Basaá. Berkeley: University of California; Manchester: University of Manchester; and Berlin: Zentrum für Allgemeine Sprachwissenschaft, Ms.

KAmP, J. A. W. 1975. Two theories about adjectives. Formal semantics of natural language, ed. by Edward Keenan, 123-55. Cambridge: Cambridge University Press.

Keenan, Edward. 1973. Logic and language. Doedalus 102.185-94.

Kennedy, Christopher. 1999. Projecting the adjective: The syntax and semantics of gradability and comparison. New York: Garland.

Kennedy, Christopher. 2001. Polar opposition and the ontology of 'degrees'. Linguistics and Philosophy 24.33-70.

Kennedy, Christopher. 2006. Comparatives, semantics. Encyclopedia of language and linguistics, 2nd edn., ed. by Keith Brown, 690-94. Oxford: Elsevier.

Kennedy, Christopher. 2007. Vagueness and grammar: The semantics of relative and absolute gradable adjectives. Linguistics and Philosophy 30.1-45.

Kennedy, Christopher, and Louise McNally. 1999. From event structure to scale structure: Degree modification in deverbal adjectives. Proceedings of Semantics and Linguistic Theory (SALT) 9.163-80. Online: http://elanguage.net/journals/salt/article/view 19.163.

Kennedy, Christopher, and Louise McNally. 2005. Scale structure, degree modification, and the semantics of gradable predicates. Language 81.2.345-81.

Kim, Yuni, and ANDrew KoontZ-Garboden. 2013. The lexical categories of Huave property concept words. Manchester: University of Manchester, MS.

KLEIN, EWAN. 1980. A semantics for positive and comparative adjectives. Linguistics and Philosophy 4.1-45.

Koontz-Garboden, Andrew. 2007. States, changes of state, and the monotonicity hypothesis. Stanford, CA: Stanford University dissertation.

Koontz-Garboden, Andrew. 2009a. Locative and existential constructions in Ulwa. Anthropological Linguistics 51.244-68.

KoOnTZ-GarbodEn, ANDREw. 2009b. Ulwa evidentials: A preliminary overview. $U B C$ Working Papers in Linguistics (The proceedings of WSCLA 13 and 14) 26.157-70. Online: http://lingserver.arts.ubc.ca/linguistics/sites/default/files/UBCWPL26-WSCLA 1314-Koonzt-Garboden.pdf.

Koontz-GARBoden, ANDREW. 2009c. Ulwa verb class morphology. International Journal of American Linguistics 75.453-512. 
Koontz-Garboden, Andrew. 2016. Thoughts on diagnosing morphomicity: A case study from Ulwa. The morphome debate: Diagnosing and analysing morphomic patterns, ed. by Ana Luís and Ricardo Bermúdez-Otero. Oxford: Oxford University Press, to appear.

Koontz-Garboden, Andrew, and Itamar Francez. 2010. Possessed properties in Ulwa. Natural Language Semantics 18.197-240.

Kratzer, Angelika. 1977. What 'must' and 'can' must and can mean. Linguistics and Philosophy 1.337-55.

Kratzer, Angelika. 1991. Modality. Semantics: An international handbook of contemporary research, ed. by Arnim von Stechow and Dieter Wunderlich, 639-50. Berlin: De Gruyter.

LinK, GODEHARD. 2002. The logical analysis of plurals and mass terms: A lattice-theoretical approach. Formal semantics: The essential readings, ed. by Paul Portner and Barbara Partee, 127-46. Oxford: Blackwell. [Originally published in Meaning, use, and interpretation of language, ed. by Rainer Bäuerle, Christoph Schwarze, and Arnim von Stechow, 302-23. Berlin: De Gruyter, 1983.]

Maiden, Martin. 2005. Morphological autonomy and diachrony. Yearbook of Morphology 2004.137-75.

MatThewson, Lisa. 2001. Quantification and the nature of crosslinguistic variation. Natural Language Semantics 9.145-89.

Minor, Eugene E., and Dorothy A. Minor. 1987. Vocabulario bilingüe Huitoto-Español, Español-Huitoto (dialecto minica). Lomalinda: Editorial Townsend. Online: http:// www.sil.org/americas/colombia/pubs/abstract.asp?id=21705.

Minor, Eugene E.; Dorothy A. Minor; and Stephen H. Levinsohn. 1982. Gramática pedagógica Huitoto. Bogotá: Ministerio de Gobierno. Online: http://www.sil.org /americas/colombia/pubs/abstract.asp?id=16189.

Moltmann, Friederike. 2009. Degree structure as trope structure: A trope-based analysis of positive and comparative adjectives. Linguistics and Philosophy 32.51-94.

Naden, Tony. 1982. Existence and possession in Bisa. Studies in African Linguistics $13.211-14$.

Newman, Paul. 2000. The Hausa language: An encyclopedic reference grammar. New Haven, CT: Yale University Press.

Nicolas, David. 2010. Towards a semantics for mass expressions derived from gradable expressions. Recherches Linguistiques de Vincennes 39. Online: http://rlv.revues.org $/ 1857$.

Pancheva, Roumyana. 2006. Phrasal and clausal comparatives in Slavic. Formal approaches to Slavic linguistics 14: The Princeton meeting 2005, ed. by James Lavine, Steven Franks, Mila Tasseva-Kurktchieva, and Hana Filip, 236-57. Ann Arbor: Michigan Slavic Publications.

PARSONS, F. W. 1955. Abstract nouns of sensory quality and their derivatives in Hausa. Afrikanistische Studien zum 80. en Geburtstag Diedrich Westermann gewidmet, ed. by J. Lukas, 373-404. Berlin: Akademie.

Parsons, Terence. 1970. An analysis of mass terms and amount terms. Foundations of Language 6.362-88.

Peters, Stanley, and Dag Westerstånl. 2006. Quantifiers in language and logic. Oxford: Oxford University Press.

Roberts, Craige. 1995. Domain restriction in dynamic semantics. Quantification in natural language, ed. by Emmon Bach, Eloise Jelinek, Angelika Kratzer, and Barbara H. Partee, 661-700. Dordrecht: Kluwer.

Rotstein, Carmen, and Yoad Winter. 2004. Total adjectives vs. partial adjectives: Scale structure and higher-order modification. Natural Language Semantics 12.259-88.

Schwarzschild, Roger, and Karina Wilkinson. 2002. Quantifiers in comparatives: A semantics of degree based on intervals. Natural Language Semantics 10.1-41.

Sellars, Wilfrid. 1967. Raw materials, subjects, and substrata. Philosophical perspectives: History of philosophy, 137-52. Reseda, CA: Ridgeview.

Stassen, Leon. 2009. Predicative possession. Oxford: Oxford University Press.

TALMY, LeONARD. 1972. Semantic structures in English and Atsugewi. Berkeley: University of California, Berkeley dissertation. 
TALMY, LEONARD. 1985. Lexicalization patterns. Language typology and syntactic description, vol. 3, ed. by Timothy Shopen, 57-149. Cambridge: Cambridge University Press.

Travis, Charles. 1989. The uses of sense: Wittgenstein's philosophy of language. Oxford: Oxford University Press.

vON FinTeL, KAI. 1994. Restrictions on quantifier domains. Amherst: University of Massachusetts dissertation.

von Fintel, Kai, and Lisa Matthewson. 2008. Universals in semantics. The Linguistic Review 25.139-201.

von Stechow, ARnim. 1984. Comparing semantic theories of comparison. Journal of Semantics 3.1-77.

WesterstÅHL, DAg. 1984. Determiners and context sets. Generalized quantifiers in natural language, ed. by Johan van Benthem and Alice ter Meulen, 45-71. Dordrecht: Foris.

WetZer, HARrie. 1996. The typology of adjectival predication. Berlin: Mouton de Gruyter. Wheeler, Samuel C. III. 1972. Attributives and their modifiers. Noûs 6.4.310-34.

[ifrancez@uchicago.edu]

[andrewkg@manchester.ac.uk]
[Received 18 July 2011;

revision invited 14 May 2012;

revision received 27 September 2012; revision invited 13 May 2013;

revision received 13 July 2013; accepted 25 March 2014] 